\title{
Überfällige Aufwertung erfolgt zaghaft und auf nicht haltbaren Grundlagen
}

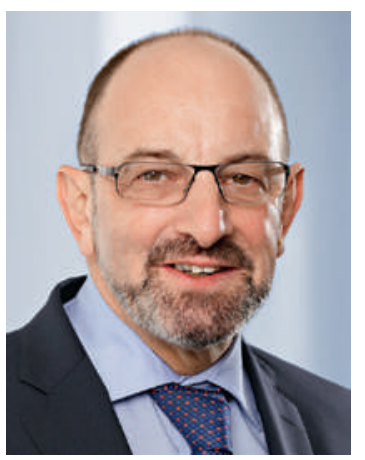

Der Bundesrat vollzieht mit dem Entscheid vom 4. November die längst überfällige Korrektur der verunglückten Revision der Analysenliste 2009 für das Praxislabor. Die FMH begrüsst dies. Sie bedauert jedoch, dass als Kalkulationsgrundlage das FMH-Kostenmodell nur unvollständig übernommen wurde. Damit erfolgt die Aufwertung nicht sachgerecht, nicht betriebswirtschaftlich gerechnet und daher nicht gesetzeskonform. Ausserdem wird die unbegründete Streichung der Präsenztaxe bei den verbleibenden Analysen unerwünschte Folgen für einige Facharztgruppen haben.

\section{Die FMH bedauert, dass als Kalkulationsgrundlage ihr Kostenmodell nur unvollständig übernommen wurde.}

Der lange Kampf für eine korrekte Abbildung und Bewertung der Tätigkeit der Praxislabor-Betreiber begann bereits nach der linearen Absenkung im Praxislabor im Rahmen der Revision der Analysenliste 2006 (AL2006). Die nachfolgende Revision der Analysenliste AL2009 unter der damaligen Ägide von Bundesrat Couchepin basierte - entgegen den Vorschlägen der FMH - auch für das Praxislabor auf der Struktur und den Datengrundlagen des Auftragslabors, obwohl die «Produk-
Praxislabor nicht sachgerecht ausgestaltet und insbesondere zu tief angesetzt ist. Im Rahmen des Masterplans für Hausarztmedizin hat sich Bundesrat Berset erfreulicherweise entschieden, das bereits 2008 vorgestellte Kostenmodell der FMH als Basis für den Point of Care-Tarif (POCT) zu verwenden. Zudem hat er für das Praxislabor eine Teilkompensation von CHF 35 Mio. beschlossen, welche seit dem 1. Januar 2014 bis zur Einführung des POCT über einen Übergangstaxpunkt abgegolten wird. Die Berechnungsgrundlagen des BAG zeigen jedoch, dass die Ärzteschaft selbst bei der Kalkulation des Übergangstaxpunktes die natürliche Mengenentwicklung tragen muss, was den Trend des BAG Richtung gesetzlich nicht vorgesehenem Globalbudget verstärkt.

Die Diskussionen betreffend das Kostenmodell der FMH wurden zwischen dem BAG und der FMH von September 2013 bis Oktober 2014 intensiv geführt. Das Original-Modell der FMH beinhaltet Positionen, welche eine sachgerechte und betriebswirtschaftlich ausgestaltete Tarifstruktur nach Gesetz ermöglichen. Nachdem die Inhalte der direkten Kosten (Reagenzienkosten, MPA-Zeiten etc.) im Modell vom BAG akzeptiert wurden, ergaben sich langwierige Diskussionen mit den «politischen» Vertretern des BAG betreffend die Abbildung der indirekten Kosten (Anteil Wartezimmer, WC etc.), die etwa 8\% der Gesamtkosten ausmachen. Da auf schriftlichem Wege keine für beide Seiten akzeptable Lösung gefunden werden konnte, hatten die «Techniker» des BAG und der FMH im Juni 2014 einen betriebswirtschaftlich gangbaren Kompromissvorschlag ausgearbeitet. Diesen akzeptierte die politische Leitung des BAG leider auch nicht: Stattdessen wird nun eine Lösung gewählt, welche Tarifstruktur und Preisbildung vermischt. Dieser Entscheid des EDI ist betriebswirtschaftlich nicht haltbar, nicht sachgerecht und somit mit den Vorgaben nicht vereinbar. Zudem streicht es

\section{Der Entscheid vom 4. November ist bereits der zweite Tarifentscheid des Bundes- rates, welcher weder sachgerecht noch betriebswirtschaftlich ist.}

tion» im Praxislabor unter deutlich anderen Voraussetzungen stattfindet. Die «kompetitiven Nachteile» des Praxislabors wollte das BAG mit Taxen und Pauschalen kompensieren. Mit der revidierten AL2009, die am 1. Juli 2009 in Kraft trat, wollte der Bundesrat sowohl die veränderten Produktionsbedingungen abbilden als auch Einsparungen von CHF 100 Mio. erreichen.

Das Monitoring des BAG ergab - wie von der FMH während der Revision vorausgesagt - beim Praxislabor je nach Spezialität Umsatzeinbussen von 18 bis 30\%. Die Einsparungen durch die AL2009 erfolgten grösstenteils beim Praxislabor; insgesamt resultierten ca. CHF 80 Mio. Umsatzeinbussen. Eine Studie des Winterthurer Instituts für Gesundheitsökonomie (WIG) zeigte klar auf, dass der Tarif für das die Präsenztaxe bei den Analysen, welche nicht nach Point of Care tarifiert werden, und benachteiligt durch diesen willkürlichen Eingriff verschiedene medizinische Fachrichtungen. Diese Punkte hatte auch die beratende Kommission von Bundesrat Berset erkannt und das Projekt zur Überarbeitung zurückgewiesen. Leider ist nun keine Anpassung mehr erfolgt.

Nach dem Tarifeingriff TARMED ist dies bereits der zweite Tarifentscheid des Bundesrates, welcher weder sachgerecht noch betriebswirtschaftlich ist.

Allem Anschein nach haben das BAG und das EDI aus den Fehlern bei der Einführung der AL2009 nichts gelernt!

Dr. med. Ernst Gähler, Vizepräsident der FMH, Departementsverantwortlicher Ambulante Tarife und Verträge Schweiz 